\title{
ARTISTIC AND AESTHETIC EDUCATION OF STUDENTS BY THE MEANS OF THE NATIONAL ARTS AND CRAFTS: THE TATARSTAN REPUBLIC EXPERIENCE
}

\author{
Anastasia V. Fakhrutdinova ${ }^{1 \star}$, Lyajsan H. Kadyjrova ${ }^{2}$, Karina I. Musina ${ }^{3}$ \\ 1Prof, Kazan (Volga Region) Federal University, RUSSIA, avfach@mail.ru \\ ${ }^{2}$ Dr, Kazan (Volga Region) Federal University, RUSSIA, leisa5614@mail.ru \\ ${ }^{3}$ Dr, Kazan (Volga Region) Federal University, RUSSIA, musinna-karina@mail.ru \\ ${ }^{*}$ Corresponding author
}

\begin{abstract}
The research is devoted to the problem of aesthetic education in contest of moral education. Aesthetic education is studied in context of Russian educational reformation (The end of XX - the beginning of XXI century) and growth of national consciousness and spiritual revival of the people. This period is suggested as an ideological return to the national cultural and historical traditions. This period is characterises by the rise of public activity towards national heritage and traditions of folk culture and art. Authors suggest and prove that the separation of education and national culture, as soon as lack of training in national-cultural issues, leads not only to local culture regression but to certain problems in international relations and national egoism. Only spiritually and morally enriched education, that means not only local language study, as it is often done in Russian Federation, but also study of traditional customs, art and values of cultural and historical traditions of local nationality (in our research Tatars), allows to teach children to appreciate the human values and spiritual achievements of other nationalities.

This means that today the educational process at schools has to be inherent in the nature of the identification of possible and effective forms and methods for the implementation of the students education on national traditions and art, as the most valuable thing for centuries, formed by the wisdom and culture of the people, should become a part of the upbringing and education of the modern school.

The authors developed the system of artistic and aesthetic education of students by means of Tatar decorative and applied arts that promote artistic and aesthetic education, development of artistic and creative abilities of students, on the basis of national consciousness of personality development. This system creates the sense of humanity of students and develops there interethnic attitudes to others. This system was implemented at a number of schools where developed course has welcomed by authorities. Students have studied a corresponding material of the Tatar arts and crafts together with their parents and teachers. The results have shown that not only the level of students' spiritual and moral education, aesthetic education has risen. The growth of their tolerance to other nation's representatives from the position of understanding of prevention every national culture peculiarities became the most amazing.
\end{abstract}

Keywords: student, education, teacher, spiritual and moral education, aesthetic education, culture, folkcreativity, decorative and applied art 


\section{INTRODUCTION}

Periods of transformation, growth of national self-consciousness and spiritual revival of the people are always connected with the return to national cultural and historical traditions. Now, when in each region of Russia we observe the rise of public national consciousness, we cannot neglect national traditions of folk culture and art. But due to the separation of education from national culture one may observe lack of national-culture issues in the school curricular. This often leads to the tension in relations between different generation, and loss of cultural heritage.

This paper presents an attempt to transmit the national cultural heritage through the organization of artistic and aesthetic education at school. In the study, special attention was given to the idea of understanding of necessity of the development of the personal qualities, of the formation of personal views, attitudes, beliefs. These became an important approach to the organisation of aesthetic education.

Special attention to the means of decorative folk arts and crafts (hereinafter referred to as FA\&C) in the educational process and in the whole process of upbringing of the younger generation is defined by the following provisions: social (Decorative FA\&C are convenient and effective means for the development of a personal culture, development of noble feelings, love to hand-craft); psychological (Decorative FA\&C, due to its proximity to children's artistic creativity and the easiness of perception by children -are effective means of harmonious development of all mental forces, imagination, creative abilities); aesthetic (addressing to Decorative FA\&C, contributes to the aspiration of goodness and truth, beauty that play an important role in development of the sense of beauty, of the aesthetic taste, of the ability to understand and appreciate works of art, the beauty of nature and surrounding reality); ecological (Decorative FA\&C, being a poetic representation of the beauty of the Earth, can bring up a feeling of love for the nature of the native land and a careful attitude toward it); patriotic (communication with the works of the Decorative FA\&C contributes young people understanding of the cultural and historical heritage of their own nation, fostering love and respect for their Fatherland, nurturing the national consciousness).

The potential of the Decorative FA\&C, its value for spiritual, moral and artistic aesthetic education is noted in a significant number of works describing the pedagogical potential of certain types of folk arts and crafts (Glinka, 2001; Chegodaeva,2012; Zheltoukhova,2014), etc.

Study of the richness of Tatar Decorative FA\&C allows one to assert its great educational opportunities for the artistic and aesthetic development of school children and a for their moral and spiritual development. Hence the idea of organization of school children artistic and aesthetic education on the basis of the use of decorative and applied art by the Tatar people is relevant to situation in society.

The teaching methodology will be based on the age-specific features of school children. This will define proposed content of the educational material that determines the choice of forms and methods of instruction. The lessons of the academic subjects should integrate with artistic and aesthetic cycle. The curriculum and extra-curricular activities, the organization of the collective and individual creative activity of the students should be correlated.

\section{METHODS}

At the first stage of the research, we studied the philosophical, historical, pedagogical, psychological, methodological literature, educational documentation that concerns the artistic and aesthetic education. Based on this study, was created a special educational program. Its idea is to maximize the implementation of the Tatar Decorative FA\&C in the block of artistic and aesthetic education. The monitoring of children's achievements, made it possible to reveal the effectiveness of using of the means of the Tatar Decorative FA\&C for artistic and aesthetic education in the educational and up-to-date space of a modern school. The study involved 78 5th grade students (children aged 11-12) at two schools: middle school No. 5 and the Tatar-Russian grammar school No. 8 - city Aznakayevo, the Republic of Tatarstan. 15 teachers from 15 schools of the Republic of Tatarstan took part in survey. The experiment lasted for 3 years.

To determine the level of Artistic and aesthetic education of students, the following criteria were defined

- psychological criteria (the ability to admire, adequate imaginative recreation and reproduction of artistic images);

- educational criteria (absence or presenting of the artistic ideal, artistic taste, the ability for imaginative thinking and artistic and aesthetic creativity);

- social criteria (the presence of an interest and the need for communication with art or aesthetic phenomena in life). 
Since we determined the potential of the Tatar Decorative FA\&C for the development of artistic and aesthetic education, it was necessary to identify the initial level of artistic and aesthetic development of students and to divide them into two groups. The first group is the one, into which children were engaged into the newly created program, the second group where children were engaged into the regular educational program of artistic and aesthetic education. The presence of two groups made it possible to monitor the transformation of the level of artistic and aesthetic education of both groups. In addition, the dynamics of the development of the level of artistic and aesthetic education of schoolchildren in both groups were measured and compared, this allowed us to generalize the evaluation of the effectiveness of the results obtained in the experiment, and draw the appropriate conclusions(Zheltoukhova, T.Yu. 2014).

To clarify the situation with the artistic and aesthetic education of students (including the means of the Tatar Decorative FA\&C, the following strategies were defined: 1) research of modern situation of the of artistic and aesthetic education at schools; 2 ) research of the experience of the best, the most creative and experienced teachers of fine arts 3 ) analytical study of modern programs on the artistic and aesthetic education of pupils of middle schools and schools with in-depth study of the subjects of the artistic and aesthetic cycle of the Russian Federation and the Republic of Tatarstan; 4) study of author's programs for the artistic and aesthetic education of students.

In order to get an idea of the actuation of general artistic and aesthetic education of schoolchildren, we used a variety of methods. Students were interviewed in order to study their literary, musical, artistic interests, the frequency of visits to museums, concerts, exhibitions, the level of their esthetic knowledge in the field of Tatar national culture and the Tatar Decorative FA\&C themselves.

\section{RESULTS}

The results of the survey of teachers of the Republic of Tatarstan (later the RT) concerning the issues of artistic and aesthetic education of students showed that the Tatar Decorative FA\&C are not or rarely used at lessons because of the lack of methodological literature on teaching methods ( $75 \%$ of teachers). Therefore, although teachers sometimes introduce the basic concepts of Tatar culture and art to students, this happens not regularly, and out of correlation with other subjects (15\% of teachers). There is no systematic and consistent approach - pupils get knowledge spontaneously, much (art ceramics, metal processing, etc.) they do not study at all (95\% of teachers). Teachers believe that in order to achieve even a minor result in involving students in the Tatar national culture and art, first of all, it is necessary to have methodological literature on the study of the Tatar Culture (95\%).

The analysis of the content of special courses and programs on the artistic and aesthetic education of the younger generation (including the means of the Tatar Decorative FA\&C) made it possible to draw the following conclusions: 1 ) in existing programs insufficient attention is paid to the national (in particular, Tatar) Decorative FA\&C; 2) the study of the national (including Tatar) Decorative FA\&C is necessary to begin at the lower grades. 3- 5 form students are considered the most favorable for mastering the material under study 3) not all aspects of the content of the Decorative FA\&C are even considered in existing programs; 4) within educational process during Artistic and aesthetic education, the interests and age characteristics of students are not sufficiently taken into account, systematic and consistent in selecting the content of the teaching material; 5) in general, the material on the Tatar DPI contained in the reviewed programs is often disjointed and does not have a methodological basis; 6 ) the forms, methods and techniques of artistic and aesthetic education of pupils of grades 3-7 do not even take into account means of the Tatar Decorative FA\&C .

The analysis of the questionnaire survey on the study of the general aesthetic culture of pupils of the 5th grades made it possible to draw the following: 1) students do not read books (exception is given to school program reading) - $78 \%$, rarely visit exhibitions - $60 \%$, theaters $-80 \%$, have little interest in art - $68 \%$, are almost unfamiliar with opera and symphony - 60\%;2) among the various types of art school children prefer video-products-100\% (most often Western production-90\%) - and music-90\% (mainly modern pop music$90 \%$, which does not quite correspond to their age), the content and aesthetic value of which often do not contribute to the development of aesthetic taste of young people; 3) a significant part of students spend their free time watching sometimes not quite children's TV shows and video films - $20 \%$, or in the internet $-80 \%$. In addition, not only the knowledge of modern school students in the field of Tatar national culture and art is very low, but even interest to get knowledge about it - is "close to zero" only $15 \%$ want to know something about it. A significant part of the students are little acquainted with folklore $-20 \%$, folk festivals of the Tatar people - $15 \%$ (the same children), do not know its artists and features of the original art of the Tatar people $50 \%$.

The search for forms and methods of artistic and aesthetic education of schoolchildren by means of the Tatar Decorative FA\&C began with the development of the contents of the training course (Mefodeva,2016). 
The educational material of the subjects of the artistic and aesthetic cycle, which the students learn, has the necessary qualities that are correlated with the general and additional requirements for content: scientific, systematic, methodological, practical, repetitive, complex, enlarged, artistic, clearly expressed by the concrete sensory content of the material (Ganieva,2015). In addition, when designing the curriculum for the lessons of the artistic and aesthetic cycle, modern requirements should be taken into account, according to which it is necessary to pay attention to the development of new types of didactic material containing and reflecting the regional-national component. It is necessary to take into account the age-specific characteristics of students, to seek to match the material to the interests, tastes, needs of schoolchildren and to ensure intersubject communications.

All the work done to develop the content of the educational material on the artistic and aesthetic education of students by the means of the Tatar Decorative FA\&C can be divided into the following stages: 1) an analysis and didactic processing of art sources on the Tatar Decorative FA\&C, works of scientists and practitioners dedicated to the practical use of the educational opportunities of the national Decorative FA\&C; 2) the development of methodical recommendations for the course "The Tatar arts and crafts for schoolchildren"; the development of a program for arts and crafts cycle where students will study the Tatar Decorative FA\&C (Kadyrova L.Kh., 1999).

Experimental testing of recommendations on the artistic and aesthetic education of students using the means of Tatar arts and crafts was accompanied by introduction into the work for teachers through seminars, practical classes and consultations, publication of materials, preparation of lectures and reports.

The content of the course "The Tatar arts and crafts for schoolchildren" includes the following sections:

5th grade -"Ornament, embroidery, gold embroidery"; "Art of leather mosaic, patterned weaving"; 6th grade -"Art ceramics and metal processing"; "National costume and jewelry art"; 7th grade -"The art of calligraphy and "shamail"; "The art of wood carving"; "Tatar folk dwelling and features of national architecture"

It should be noted that the teaching of this course at school is provided at the expense of the time devoted to the lessons of fine arts (12 hours out of 64 in a year) at grades 5-7.

The diagnostic procedure assumed an assessment of the results of the dynamics of the artistic and aesthetic education of schoolchildren in two main directions: the dynamics of the overall artistic and aesthetic development of the student's personality (the level of artistic and aesthetic knowledge and the level of artistic and aesthetic activity) and the dynamics of the level of knowledge of students in the field of Tatar culture and art (in particular of the Tatar people).

Forms of artistic and aesthetic education of students, used in our experimental work, are based on: the synthesis of individual and group forms of artistic and aesthetic activity of students; the idea of out-ofclassroom activities (lessons in local history museums, at exhibitions of works of Tatar folk art, visits to the workshops of Tatar folk applied artists), and creativity (Kondrateva I, Fakhrutdinova A., 2016).

The analysis of the results obtained at the final stage of the forming experiment showed that during the work carried out in the experimental group 1 a steady tendency of improvement was found in the indicators of the artistic and aesthetic education of students. A comparative analysis of the results obtained at the beginning and at the end of the experimental work carried out in the experimental group 1 is presented in the form of the following tables (Table1).

Table 1. Dynamics of the level of artistic and aesthetic development of school students (who were studied by the new program)

\begin{tabular}{|c|c|c|}
\hline Levels & $\begin{array}{c}\text { Beginning of the } \\
\text { experiment(2013)\% }\end{array}$ & End of experiment(2016)\% \\
\hline high & 20 & 64 \\
\hline average & 54 & 4 \\
\hline low & 26 & 64 \\
\hline
\end{tabular}

A comparative analysis of the results obtained at the beginning and at the end of the experimental work carried out in the experimental group 2- students who were studied by the old program is presented in the form of the following tables (Table2). 
IJAEDU- International E-Journal of Advances in Education, Vol. 3, Issue 8, August 2017

Table 2. Dynamics of the level of artistic and aesthetic development of school students (who were studied by the old program)

\begin{tabular}{|c|c|c|}
\hline Levels & $\begin{array}{c}\text { Beginning of the } \\
\text { experiment(2013)\% }\end{array}$ & End of experiment(2016)\% \\
\hline high & 21 & 65 \\
\hline average & 60 & 8 \\
\hline low & 19 & 27 \\
\hline
\end{tabular}

\section{DISCUSSIONS}

Artistic and aesthetic education by the means of the Tatar Decorative FA\&C at different stages of training should be structured differently taking into account the logic of the subject itself and, of course, the agerelated psychological, characteristics of students(Komarova,1997). In our opinion, it should be based on the following principles: 1) reliance on the leading provisions of modern educational theory and psychology; 2) identification of the main features and characteristics of the national Decorative FA\&C; 3) taking into account age characteristics and abilities of students when selecting materials on the national Decorative FA\&C; 4) a lot of educational time should be given to individual work with the child in the process of collective artistic and practical studies; 5) a combination of theoretical and practical forms of involving students in the national Decorative FA\&C should be used.

The adolescent stage of the artistic and aesthetic activity of children in general can be characterized as analytical. The desire of a teenager to master the "standards" of human activity and behavior creates good conditions for familiarizing him/her with artistic culture. A teenager should also have an opportunity to test himself in various types of artistic and creative practice, expressing himself in socially significant results activity. Therefore, tasks should be quite complex and contribute to the development of his creative abilities. It should be remembered that the display of photographic materials (and, better than the originals) of5) the national Decorative FA\&C should be used.

Visit to the workshop of folk craftsmen, and the use of real materials in the workplace constitute one of the essential factors for activating the respective attitude of adolescents to the Decorative FA\&C(Styopina, 2010).

Considering the above, and relying on the recommendations of the existing programs on fine arts and labor training, we believe it is also advisable to offer children a decorative drawing, as well as the following types of artistic and practical activities to study the Tatar Decorative FA\&C by pupils at grades 5-7 - applications from various materials, "collage", art of calligraphy, modeling, printing, work with cloth, carving and painting on wood, paper plastic, embroidery, burning, decoration. Thus, we tried to diversify the materials used during the lessons, cognitive information, manual operations, types of artistic and practical activity, relying on the well-known opinion that the wider the range of operations that children master, the better and more versatile is the coordination of hand movement(Fakhrutdinova,2016). Despite the long history and the existence of proven methods and forms, the practice of artistic and aesthetic education of schoolchildren, requires adaptation to modern conditions, technologies and resources. The pedagogical potential of Tatar decorative and applied art as a means of artistic and aesthetic education of students lies in its accessibility and closeness to children's creativity, which makes it possible to form the artistic taste of a child, raise the level of his/her artistic and aesthetic education, and a sense of humanity in the sphere of interethnic relations.

\section{CONCLUSIONS}

The obtained results of the experimental work made it possible to assert that the artaesthetic education by the means of the Tatar Decorative FA\&C of the students is more productive than the use of old, unified programs. The proposed system of artistic and aesthetic education of students by means of the Tatar Decorative FA\&C helped to raise the level of artistic and aesthetic education, to develop the artistic and creative abilities of schoolchildren, to develop the national self-awareness of the individual, and raise the sense of humanity in the sphere of interethnic relations. The introduction of the developed course in a number of schools aroused the satisfaction of students who studied the Tatar Decorative FA\&C, their parents and teachers. 


\section{REFERENCE LIST}

Chegodaeva, M. 2012 Art that was. The approaches of Russian book graphics 1917-1936.

$\mathrm{SPb}$ Galart, 384p.

Fakhrutdinova Anastasia V., Makhmutova Madina M. and Nurkhamitov Marsel R., 2016. National SelfAwareness of Tatar Youth in Diaspora: Historical Approach. The Social Sciences, 11: 6800-6804.

Ganieva Yoldyz N., Structure and content of higher professional school lecturer education competence / Guzel B. Sayfutdinova, Aislu B. Yunusova, Victoriya V. Sadovaya, Neile K. Schepkina, Natalya Y.Scheka, Evgeniya V. Gutman, Valentina B. Salakhova // Review of European Studies. - 2015. - №4. - C. 32 - 38.

Glinka, N. 2001 Conversations about Russian art. XVIII century. M. 272p.

Komarova. T.S.,1997 Folk art in the education of children.1997 A book for teachers of preschool institutions, primary school teachers Moscow: Publishing house of the Russian Pedagogical Agency, 1997. - 208 p.

Kadyrova L.Kh., 1999 Artistic and aesthetic education of students of grades 1-7 using the means of Tatar decorative and applied art. The dissertation author's abstract on competition of the candidate of pedagogical sciences. - Kazan, 1999. - $26 \mathrm{p}$.

Kondrateva I, Fakhrutdinova A., 2016 Modeling Teachers Multicultural Identity through Studying A Foreign

Language //The European Proceedings of Social \& Behavioural Sciences EpSBS Volume XII, Pages $1-\mathrm{X}$ (Juy 2016) e-ISSN: 2357-1330, p. 245-250, IFTE 2016 - 2nd International Forum on Teacher Education Dates: 19-21 May 2016 Location: Kazan Federal University, Russia,Future Academy www.FutureAcademy.org.uk

Mefodeva, M.A., Fakhrutdinova, A.V., Zakirova, R.R., 2016 Moral education in Russia and India: A comparative analysis Social Sciences 11(15) pp.3765-3769

Styopina, T.A. 2010 Artistic and aesthetic education and education in school.-http://www.kursksosh35.ru/obychenie/metod-kopilka/41-vneklassnaya-rabota/655-xudozhestvenno-esteticheskoevospitanie-i-obrazovanie-v-shkole.html

Zheltoukhova, T.Yu. 2014 Improvement of Design of Art Articles from the Stone With Application of Transformation of Natural Forms of The Abstract of The Candidate of T echnical Sciences degree Thesisis St. Petersburg. 19p. 